\title{
Determination of the effect of brand and product identification on consumer palatability ratings of ground beef patties $1,2,3$
}

\author{
A. K. Wilfong, K. V. McKillip, J. M. Gonzalez, \\ T. A. Houser, J. A. Unruh, E. A. E. Boyle, and T. G. O'Quinn ${ }^{4}$ \\ Department of Animal Sciences and Industry, Kansas State University, Manhattan 66506
}

\begin{abstract}
The objective of this study was to determine the effect of brand and product identification on consumer palatability ratings of ground beef patties. Six treatments were used in the study: 90/10 Certified Angus Beef (CAB) ground sirloin, 90/10 ground beef, 80/20 CAB ground chuck, 80/20 ground chuck, 80/20 ground beef, and 73/27 $\mathrm{CAB}$ ground beef. Ground beef was processed into $151.2-\mathrm{g}$ patties using a patty former with 2 consecutively formed patties assigned to blind consumer testing and the following 2 assigned to informed testing. Following cooking to $74^{\circ} \mathrm{C}$, patties were cut into quarters and served to consumers. Consumers $(n=112)$ evaluated samples in 2 rounds for tenderness, juiciness, flavor liking, texture liking, and overall liking. Each trait was also rated as either acceptable or unacceptable. In the first round of testing, samples were blind evaluated, with no information about the treatments provided to consumers, but in the second round, product type and brand were disclosed prior to sample evaluation. Additionally, texture profile and shear force analyses were performed on patties from each treatment. Few differences were observed
\end{abstract}

for palatability traits during blind consumer testing; however, during informed testing, 90/10 CAB ground sirloin was rated greatest $(P<0.05)$ for all palatability traits other than juiciness. Also, 90/10 CAB ground sirloin had increased $(P<0.05$; (consumer informed score - consumer blind score)/consumer blind score) ratings for tenderness $(17.4 \%)$, juiciness $(36.5 \%)$, flavor liking (23.3\%), texture liking (18.2\%), and overall liking $(24.7 \%)$ due to brand disclosure. Increased $(P<0.05)$ ratings were found for $\mathrm{CAB}$ products for multiple traits due to treatment disclosure, whereas the only non-CABbranded product that received increased $(P<0.05)$ ratings during informed testing was $90 / 10$ ground beef for tenderness and juiciness. Texture results indicated that decreased fat level increased hardness, cohesiveness, gumminess, and chewiness. These results indicate that when sampling ground beef without brand and product information, few consumers find differences in eating quality among ground beef treatments; however, when consumers are aware of the brand, fat level, and subprimal blend prior to sampling, these factors have a large impact on consumer eating satisfaction.

Key words: Angus, branding, consumer, ground beef, palatability, texture profile analysis

J. Anim. Sci. 2016.94:4943-4958 doi:10.2527/jas2016-0894

\section{INTRODUCTION}

\footnotetext{
${ }^{1}$ Funded by the Angus Foundation, 3201 Frederick Ave., St. Joseph, MO 64506, and Certified Angus Beef LLC, 206 Riffel Rd., Wooster, OH 44691.

${ }^{2}$ The authors have no conflict of interest to declare for this research.

${ }^{3}$ Contribution number 17-025-J of the Kansas Agricultural Experiment Station, Manhattan, KS 66506.

${ }^{4}$ Corresponding author: travisoquinn@ksu.edu

Received August 10, 2016.

Accepted September 1, 2016
}

Ground beef is one of the least expensive beef products sold in the United States and represents the largest volume in pounds of beef sold in the food service industry, at $64 \%$, and represents more than $37 \%$ of revenue sales for both food service and retail industries (Speer et al., 2015). Additionally, ground beef prices have steadily increased over the past decade, with a much more rapid increase in value over the past 5 yr (Speer et al., 2015). Traditionally, ground beef has 
been marketed as a commodity product; however, with retail ground beef prices eclipsing $\$ 8.82 / \mathrm{kg}$ this past year (Bureau of Labor Statistics, 2016), many retailers and suppliers are looking for ways to capture additional value from this category. In 2010, 51\% of ground beef at retail was marketed without a brand (National Cattlemen's Beef Association et al., 2010). This large number of unbranded products represents an opportunity for product differentiation and value creation in this segment.

Branding can be used to indicate increased quality level associated with products and, in some cases, encourages consumers to pay a premium to receive a superior product (Grunert et al., 2004). Branding previously has been shown to have a large impact on the eating quality of pasta noodles, chicken breast meat, and beer (Allison and Uhl, 1964; Di Monaco et al., 2004; Samant and Seo, 2016), although the effect of branding on ground beef palatability is currently unknown. Published literature evaluating the impact of fat level and primal-specific blends on ground beef palatability have produced mixed results (Berry, 1992; McHenry, 2013; Kerth et al., 2015) and no studies have evaluated the impact of informing consumers of these factors on eating quality. Therefore, the objective of this study was to determine the effect of branding on consumer perceptions of ground beef palatability and determine the palatability-related impact associated with fat level, primal-specific blend, and Certified Angus Beef (CAB) branding.

\section{MATERIALS AND METHODS}

\section{Ground Beef Treatments and Preparation}

Six treatments (six 4.54-kg chubs/treatment) were chosen to represent a variety of product types and fat levels (represented as lean percentage/fat percentage) and included 90/10 CAB ground sirloin, 90/10 ground beef, 80/20 CAB ground chuck, 80/20 ground chuck, 80/20 ground beef, and 73/27 CAB ground beef. Treatments were procured from a commercial processing facility in the Midwest, transported under refrigeration to the Kansas State University (KSU) Meat Laboratory (Manhattan, $\mathrm{KS}$ ), and stored at 0 to $4^{\circ} \mathrm{C}$ prior to patty formation.

Ground beef chubs (fine ground; 3.2- $\mathrm{mm}$ grinder plate) were fabricated on the same day on an average of $8 \mathrm{~d}$ from the packaging date into 151.2-g (approximately $13 \mathrm{~cm}$ diameter and $1 \mathrm{~cm}$ thick) patties using a patty former (Super Model 54 Food Portioning Unit; Hollymatic Corporation, Countryside, IL). Each chub was individually processed. Following patty formation, ground beef patties were assigned to consumer testing (patties 1 and 2 for blind testing and patties 3 and 4 for informed testing), proximate analysis (patty 5), shear force analysis (patty 6), objective juiciness testing (data not reported; patty 7), cooked volatile compound analysis (data not reported; patty 8), and texture profile analysis (patty 9). Patties were then identified, vacuumpackaged, and frozen $\left(-20^{\circ} \mathrm{C}\right)$ until analysis.

\section{Consumer Panel Testing}

The KSU Institutional Review Board approved procedures for use of human subjects for sensory panel evaluations (Institution Review Board number 7440). Consumer testing was conducted in Manhattan, KS, at the KSU Animal Science building. Consumer panelists $(n=112)$ were paid to participate in the study, were recruited from Manhattan and the surrounding communities, and were allowed to participate only once. Consumers sampled ground beef patties under florescent lighting in a large lecture-style room. Five sessions of panels, each lasting about $1.5 \mathrm{~h}$, were conducted with 21 consumers present at each and 1 panel consisting of only 7 consumers.

Consumers were asked to complete a demographic questionnaire that provided information about gender, household size, income level, education level, ethnicity, beef consumption habits, and flavor preferences prior to testing. Along with demographics, consumers rated the importance of 15 different fresh beef purchasing motivators that included various beef product and production claims on 100-mm line scales, with 0 anchored as "extremely unimportant" and 100 anchored as "extremely important." The 15 purchasing motivators and the associated scales were listed in a random order, with the statement "please rate the importance of each trait when purchasing fresh beef" listed at the top of the ballot. Consumers were provided a ballot, a fork, a knife, and an expectorant cup as well as unsalted crackers and apple juice to use as palate cleansers between samples. Prior to testing, participants were given verbal instructions about the ballot, testing procedures, and the use of palate cleansers.

Patties were thawed at 2 to $4^{\circ} \mathrm{C}$ for $24 \mathrm{~h}$ prior to consumer testing and cooked to $74^{\circ} \mathrm{C}$ in a $163^{\circ} \mathrm{C}$ convection oven (DFG-100-3 Series; G.S. Blodgett Corporation, Burlington, VT) with patty endpoint temperature verified using a probe thermometer (model 450ATT; OMEGA Engineering, Stamford, CT). Following cooking, patties were cut into 4 equally sized wedges and 7 predetermined consumers received 1 wedge each.

Ground beef samples were served in 2 rounds. In the first round, consumers were served all samples "blind," with no information about the samples provided to the consumers prior to evaluation. In the second round, immediately prior to sample evaluation, consumers were verbally informed of the treatment in- 
Table 1. Shear force and proximate composition for ground beef of differing brands, lean percentages, and subprimal sources

\begin{tabular}{|c|c|c|c|c|c|}
\hline Treatment $^{1}$ & Shear force, $\mathrm{kg}$ & Moisture, $\%$ & Protein, $\%$ & Fat, \% & Ash, $\%$ \\
\hline $90 / 10$ ground beef & $4.4^{\mathrm{a}}$ & $70.3^{\mathrm{a}}$ & $20.3^{\mathrm{ab}}$ & $10.1^{\mathrm{c}}$ & $1.0^{\mathrm{b}}$ \\
\hline $90 / 10 \mathrm{CAB}^{2}$ ground sirloin & $3.0^{\mathrm{c}}$ & $69.4^{\mathrm{a}}$ & $20.7^{\mathrm{a}}$ & $8.7^{\mathrm{d}}$ & $1.6^{\mathrm{a}}$ \\
\hline $80 / 20$ ground beef & $3.9^{\mathrm{b}}$ & $64.8^{\mathrm{b}}$ & $19.3^{\mathrm{bc}}$ & $16.9^{\mathrm{b}}$ & $0.9^{\mathrm{bc}}$ \\
\hline $80 / 20$ ground chuck & $3.9^{\mathrm{b}}$ & $63.5^{\mathrm{b}}$ & $19.1^{\mathrm{bc}}$ & $17.0^{\mathrm{b}}$ & $0.9^{\mathrm{b}}$ \\
\hline $80 / 20 \mathrm{CAB}$ ground chuck & $3.8^{\mathrm{b}}$ & $63.5^{\mathrm{b}}$ & $18.8^{\mathrm{c}}$ & $17.2^{\mathrm{b}}$ & $1.0^{\mathrm{b}}$ \\
\hline $73 / 27 \mathrm{CAB}$ ground beef & $3.2^{\mathrm{c}}$ & $57.8^{\mathrm{c}}$ & $18.4^{\mathrm{c}}$ & $25.2^{\mathrm{a}}$ & $0.7^{\mathrm{c}}$ \\
\hline SEM $^{3}$ & 0.1 & 0.8 & 0.5 & 0.3 & 0.1 \\
\hline$P$-value & $<0.01$ & $<0.01$ & $<0.01$ & $<0.01$ & $<0.01$ \\
\hline
\end{tabular}

formation (brand, primal source, and lean point), with labels presented on ballots and on a projector screen in the front of the room. For $\mathrm{CAB}$ products, the full-color $\mathrm{CAB}$ logo was used for brand identification. All subprimal information and fat percentages were presented in identical text, with only the specific product names differing between treatments. Other than the treatment identification, no other information was provided on the labels. In each round, consumers evaluated $1 \mathrm{sam}-$ ple from each of the 6 treatments, in a random order. Moreover, consumer ballots were collected following the first round of testing and consumers were provided separate ballots for the second round of testing. Samples evaluated in round 2 for each consumer were from the same chubs as samples evaluated in the first round, allowing a direct comparison of consumer ratings and the effect of disclosing fat percentage, subprimal, and brand on palatability perception.

For both rounds of testing, samples were evaluated for tenderness, juiciness, texture liking, flavor liking, and overall liking on 100-mm line scales anchored with descriptive terms at the ends and midpoints: $100=$ extremely juicy, tender, and like flavor/texture/overall extremely; $50=$ neither juicy nor dry, tough nor tender, and neither like or dislike flavor/texture/overall; and $0=$ extremely tough, dry, and dislike flavor/texture/ overall extremely. Additionally, consumers rated each trait as either acceptable or unacceptable as well as identified the sample as unsatisfactory, everyday quality, better than everyday quality, or premium quality.

\section{Shear Force Testing}

Patties for shear force testing were cooked as previously described for consumer testing. Methods from the Research Guidelines for Cookery, Sensory Evaluation, and Instrumental Tenderness Measurements of Meat (AMSA, 2015) were used for shear force testing of ground beef patties. Briefly, following cooking, samples were allowed to cool to room temperature $\left(21-23^{\circ} \mathrm{C}\right)$ prior to shearing. Shear force was measured on 2 strips $(2.5 \mathrm{~cm}$ wide $\times$ patty thickness) that were removed from the center across the width of the patty. Each strip was sheared (crosshead speed of $250 \mathrm{~mm} / \mathrm{min}$ ) perpendicular to the cooked surface at 3 locations along the strip, using a straight edge slice-shear force blade attached to an INSTRON model 5569 testing machine (Instron, Canton, MA). Shear force values were recorded in kilograms and the 6 readings were averaged for each patty.

\section{Texture Profile Analysis}

Texture profiling of ground beef patties was conducted using the methods described by the American Meat Science Association (2015). Cooking of patties was performed as described for consumer panel testing. Patties were allowed to cool to room temperature $\left(21-23^{\circ} \mathrm{C}\right)$ before three $2.54-\mathrm{cm}$ cores were removed through the cooked surface in the center of each patty. Each core was then compressed to $70 \%$ of its original height in 2 cycles, using an INSTRON model 5569 testing machine. Chewiness, springiness, gumminess, hardness, and cohesiveness were calculated using the methods of Bourne (1978).

\section{Proximate Analysis}

Patties used for proximate analysis were thawed for $24 \mathrm{~h}$ at 2 to $4^{\circ} \mathrm{C}$. Each sample was frozen in liquid nitrogen and homogenized using a commercial 4-blade blender (model 33BL 79; Waring Products, New Hartford, CT). The homogenate was transferred to Whirl-Pak bags (Nasco, Ft. Atkinson, WI) and stored in a $-20^{\circ} \mathrm{C}$ freezer until subsequent analysis. Moisture and fat were analyzed using an AOAC official method (985.14 (A2); AOAC, 2005) by micro- 
Table 2. Texture profile analysis ${ }^{1}$ results for ground beef treatments

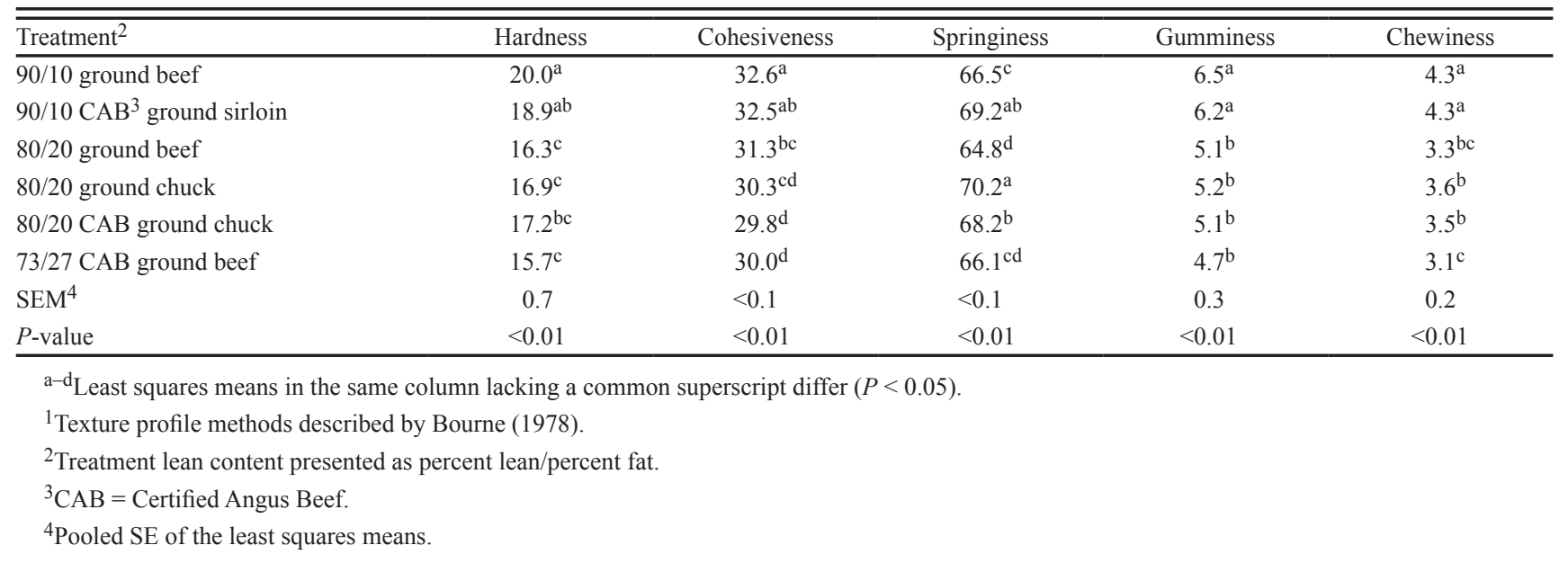

wave radiation (CEM Corp.). Protein was calculated following an AOAC official method (990.03, 2002; AOAC, 2005) using a LECO TruMac $\mathrm{N}$ analyzer (LECO Corporation, St. Joseph, MI). A muffle furnace was used for ash determination following the methods of the AOAC (2005; 920.153-1920).

\section{Statistical Analysis}

Statistical analyses were conducted using SAS (version 9.4; SAS Inst. Inc., Cary, NC). Consumer panel data were analyzed using PROC GLIMMIX with an $\alpha$ $=0.05$. The model included the fixed effect of treatment and the random effect of panel session number. A model with a binomial error distribution was used for analysis of all acceptability data. For shear force and texture data, patty peak cooked temperature was included in the model as a covariate. All consumer demographics were summarized using PROC FREQ. Pearson correlation coefficients were calculated and tested using PROC CORR. Denominator degrees of freedom were estimated using the Kenward-Roger approximation for all consumer panel, shear force, and proximate analyses.

\section{RESULTS}

\section{Proximate Analysis, Shear Force, and Texture Profile Analysis}

Differences $(P<0.05)$ were found among treatments for all proximate measurements (Table 1). As expected, fat analysis indicated 73/27 CAB ground beef had the greatest $(P<0.05)$ amount of fat, with $90 / 10 \mathrm{CAB}$ ground sirloin having the least $(P<0.05)$ fat, which was lower $(P$ $<0.05)$ than that of the $90 / 10$ ground beef. Additionally, all 80/20 treatments were similar $(P>0.05)$ in fat content. Moisture percentage decreased $(P<0.05)$ as fat percentage increased, with all treatments at the same fat level having a similar $(P>0.05)$ moisture content. Protein percentage was higher $(P<0.05)$ for $90 / 10 \mathrm{CAB}$ ground sirloin compared with all treatments except $90 / 10$ ground beef, and no differences $(P>0.05)$ were found among the four $80 / 20$ and $73 / 27$ treatments for protein percentage. Ash percentage was also the greatest $(P<0.05)$ for 90/10 CAB ground sirloin samples, whereas $73 / 27$ CAB ground beef had a lower $(P>0.05)$ ash percentage than all treatments except $80 / 20$ ground beef.

The 90/10 ground beef had the greatest $(P<0.05)$ shear force compared with all other treatments (Table 1). All three 80/20 ground beef treatments were similar $(P>$ $0.05)$ in shear force values for cooked patties and tougher $(P<0.05)$ than $73 / 27 \mathrm{CAB}$ ground beef. Additionally, 90/10 CAB ground sirloin was similar $(P>0.05)$ to $73 / 27$ $\mathrm{CAB}$ ground beef for shear force and more tender $(P<$ 0.05 ) than all other treatments.

Texture profile analysis indicated cohesiveness, hardness, gumminess, and chewiness generally decreased as fat level of ground beef increased (Table 2). Texture profile analysis results of the 6 treatments of ground beef indicated gumminess and chewiness were greatest $(P<0.05)$ for $90 / 10$ ground beef and 90/10 CAB ground sirloin samples. Also, 90/10 ground beef had greater $(P<0.05)$ hardness values than all other treatments except $90 / 10 \mathrm{CAB}$ ground sirloin. Springiness was greater $(P<0.05)$ for $90 / 10 \mathrm{CAB}$ ground sirloin, $80 / 20$ CAB ground chuck, and 80/20 ground chuck than the other 3 treatments. Cohesiveness was greater $(P<0.05)$ for $90 / 10$ ground beef when compared with all treatments other than 90/10 CAB ground sirloin. Additionally, 73/27 CAB ground beef and 80/20 CAB ground chuck were less $(P<0.05)$ cohesive than all of the treatments other than $80 / 20$ ground chuck. 
Table 3. Demographic characteristics of consumers $(n=112)$ who participated in ground beef sensory panels

\begin{tabular}{|c|c|c|}
\hline Characteristic & Response & $\begin{array}{c}\text { Percentage of } \\
\text { consumers }\end{array}$ \\
\hline \multirow[t]{2}{*}{ Sex } & Male & 52.8 \\
\hline & Female & 47.2 \\
\hline \multirow[t]{7}{*}{ Household size } & 1 person & 9.9 \\
\hline & 2 people & 31.5 \\
\hline & 3 people & 17.1 \\
\hline & 4 people & 19.8 \\
\hline & 5 people & 13.5 \\
\hline & 6 people & 1.8 \\
\hline & Over 6 people & 6.3 \\
\hline \multirow[t]{2}{*}{ Marital status } & Single & 29.6 \\
\hline & Married & 70.4 \\
\hline \multirow[t]{6}{*}{ Age group } & Under 20 & 9.2 \\
\hline & $20-29$ & 18.4 \\
\hline & $30-39$ & 25.7 \\
\hline & $40-49$ & 22.0 \\
\hline & $50-59$ & 15.6 \\
\hline & Over 60 & 9.2 \\
\hline \multirow[t]{4}{*}{ Ethnic origin } & African American & 1.8 \\
\hline & Asian & 3.7 \\
\hline & Caucasian/white & 90.8 \\
\hline & Hispanic & 3.7 \\
\hline \multirow{5}{*}{$\begin{array}{l}\text { Annual household } \\
\text { income, \$ }\end{array}$} & 25,000 to 24,999 & 11.0 \\
\hline & 35,000 to 49,999 & 10.1 \\
\hline & 50,000 to 74,999 & 25.7 \\
\hline & 75,000 to 100,000 & 26.6 \\
\hline & More than 100,000 & 26.6 \\
\hline \multirow{5}{*}{$\begin{array}{l}\text { Highest level of } \\
\text { education completed }\end{array}$} & Non-high school graduate & 5.6 \\
\hline & High school graduate & 9.4 \\
\hline & Some college/technical school & 34.6 \\
\hline & College graduate & 29.0 \\
\hline & Postgraduate & 21.5 \\
\hline \multirow{3}{*}{$\begin{array}{l}\text { Weekly beef } \\
\text { consumption }\end{array}$} & 1 to 3 times & 42.7 \\
\hline & 4 to 6 times & 53.6 \\
\hline & 7 or more times & 3.6 \\
\hline \multirow{3}{*}{$\begin{array}{l}\text { Most important } \\
\text { palatability trait } \\
\text { when eating beef }\end{array}$} & Flavor & 69.7 \\
\hline & Juiciness & 9.2 \\
\hline & Tenderness & 21.1 \\
\hline \multirow{8}{*}{$\begin{array}{l}\text { Meat product most } \\
\text { preferred for flavor }\end{array}$} & Beef & 58.3 \\
\hline & Chicken & 14.8 \\
\hline & Fish & 0.9 \\
\hline & Lamb & 6.5 \\
\hline & Pork & 9.3 \\
\hline & Shellfish & 5.6 \\
\hline & Turkey & 2.8 \\
\hline & Venison & 1.9 \\
\hline
\end{tabular}

\section{Consumer Demographics and Purchasing Motivators}

Consumer demographic information from panelists who sampled ground beef is displayed in Table 3. There were slightly more males $(52.8 \%)$ than females (47.2\%). Moreover, the large majority was Caucasian/
Table 4. Fresh beef purchasing motivators of consumers $(n=112)$ who participated in consumer sensory panels

\begin{tabular}{lc}
\hline \hline Characteristic & Importance of trait ${ }^{1}$ \\
\hline Price & $73.8^{\mathrm{a}}$ \\
Size, weight, and thickness & $68.6^{\mathrm{ab}}$ \\
Steak color & $67.0^{\mathrm{bc}}$ \\
Familiarity of cut & $62.2^{\mathrm{bcd}}$ \\
USDA grade & $62.1^{\mathrm{bcd}}$ \\
Marbling level & $60.8^{\mathrm{cd}}$ \\
Nutrient content & $55.5^{\mathrm{d}}$ \\
Country of origin & $48.4^{\mathrm{e}}$ \\
Local & $46.1^{\mathrm{e}}$ \\
Eating satisfaction claims & $46.0^{\mathrm{e}}$ \\
(example: "Guaranteed Tender") & \\
Animal welfare & $43.5^{\mathrm{ef}}$ \\
Antibiotic use in the animal & $43.3^{\mathrm{ef}}$ \\
Brand of product & $42.6^{\mathrm{efg}}$ \\
Growth promotant use in the animal & $37.9^{\mathrm{fg}}$ \\
Natural and organic claims & $36.3^{\mathrm{g}}$ \\
SEM ${ }^{2}$ & 2.4 \\
$P$-value & $<0.01$ \\
\hline a-g Least squares means lacking a common superscript differ $(P<0.05)$. \\
${ }^{1}$ Purchasing motivators: $0=$ extremely unimportant and $100=\mathrm{ex}-$ \\
tremely important. & \\
2Pooled SE of the least squares means. &
\end{tabular}

white $(90.8 \%)$, was married $(70.4 \%)$, and had a household size of 3 or more people (52.2\%). More than half (53.2\%) of consumers had an annual household income greater than $\$ 75,000$ and half $(50.5 \%)$ were at least college graduates. Beef was the most popular meat flavor preferred by consumers $(58.3 \%)$ followed by chicken $(14.8 \%)$ and pork $(9.3 \%)$. Most of the consumers $(53.6 \%)$ consumed beef 4 to 6 times a week. Flavor was the preferred palatability trait of $69.7 \%$ of consumers followed by tenderness $(21.1 \%)$ and juiciness $(9.2 \%)$.

Consumers who participated in sensory panels considered "price" to be more $(P<0.05)$ important when purchasing fresh beef than all other traits; however, this characteristic was not different than all other traits evaluated except "size, weight, and thickness" (Table 4). Product-related characteristics of "steak color," "familiarity of cut," "USDA grade," "marbling level," and "nutrient content" were more important $(P<0.05)$ than "country of origin," "local," "eating satisfaction claims," "animal welfare," "antibiotic use in the animal," and "brand of the product." "Natural and organic claims" was one of the least important purchasing motivators to consumers but was rated similar $(P>0.05)$ to "brand of product" and "growth promotant use in the animal."

\section{Consumer Palatability Ratings}

Consumer palatability ratings for ground beef are presented in Table 5. Few differences were ob- 
Table 5. Consumer $(n=112)$ palatability ratings ${ }^{1}$ for blind and informed testing of ground beef patties

\begin{tabular}{|c|c|c|c|c|c|}
\hline Treatment $^{2}$ & Tenderness & Juiciness & Flavor liking & Texture liking & Overall liking \\
\hline \multicolumn{6}{|l|}{ Blind testing } \\
\hline $90 / 10$ ground beef & $52.1^{\mathrm{b}}$ & $45.7^{\mathrm{b}}$ & 57.1 & 55.4 & 55.7 \\
\hline $90 / 10 \mathrm{CAB}^{3}$ ground sirloin & $60.9^{\mathrm{a}}$ & $47.2^{\mathrm{b}}$ & 59.8 & 60.1 & 59.3 \\
\hline $80 / 20$ ground beef & $61.8^{\mathrm{a}}$ & $58.4^{\mathrm{a}}$ & 60.8 & 59.3 & 61.7 \\
\hline $80 / 20$ ground chuck & $61.6^{\mathrm{a}}$ & $55.0^{\mathrm{a}}$ & 61.2 & 58.7 & 59.5 \\
\hline 80/20 CAB ground chuck & $58.5^{\mathrm{a}}$ & $52.4^{\mathrm{ab}}$ & 54.0 & 57.4 & 57.0 \\
\hline $73 / 27 \mathrm{CAB}$ ground beef & $62.2^{\mathrm{a}}$ & $56.9^{\mathrm{a}}$ & 57.3 & 56.5 & 58.8 \\
\hline SEM $^{4}$ & 2.3 & 3.0 & 2.7 & 2.2 & 2.5 \\
\hline$P$-value & 0.01 & $<0.01$ & 0.25 & 0.62 & 0.56 \\
\hline \multicolumn{6}{|l|}{ Informed testing } \\
\hline $90 / 10$ ground beef & $57.1^{\mathrm{c}}$ & $51.6^{\mathrm{b}}$ & $60.7^{\mathrm{b}}$ & $57.7^{\mathrm{b}}$ & $59.4^{\mathrm{b}}$ \\
\hline 90/10 CAB ground sirloin & $71.2^{\mathrm{a}}$ & $62.0^{\mathrm{a}}$ & $72.5^{\mathrm{a}}$ & $69.7^{\mathrm{a}}$ & $72.2^{\mathrm{a}}$ \\
\hline $80 / 20$ ground beef & $61.4^{\mathrm{bc}}$ & $62.2^{\mathrm{a}}$ & $61.6^{\mathrm{b}}$ & $58.5^{\mathrm{b}}$ & $61.6^{\mathrm{b}}$ \\
\hline $80 / 20$ ground chuck & $60.1^{b c}$ & $56.8^{\mathrm{ab}}$ & $58.9^{\mathrm{b}}$ & $57.9^{\mathrm{b}}$ & $59.8^{\mathrm{b}}$ \\
\hline 80/20 CAB ground chuck & $61.7^{\mathrm{bc}}$ & $58.7^{\mathrm{a}}$ & $63.7^{\mathrm{b}}$ & $60.1^{\mathrm{b}}$ & $62.8^{\mathrm{b}}$ \\
\hline $73 / 27 \mathrm{CAB}$ ground beef & $64.1^{\mathrm{b}}$ & $62.4^{\mathrm{a}}$ & $59.4^{\mathrm{b}}$ & $59.7^{\mathrm{b}}$ & $59.7^{\mathrm{b}}$ \\
\hline $\mathrm{SEM}^{4}$ & 2.3 & 2.3 & 2.2 & 1.8 & 1.9 \\
\hline$P$-value & $<0.01$ & 0.01 & $<0.01$ & $<0.01$ & $<0.01$ \\
\hline
\end{tabular}

${ }^{\mathrm{a}-\mathrm{c}}$ Least squares means in the same section (blind or informed) of the same column and lacking a common superscript differ $(P<0.05)$.

${ }^{1}$ Sensory scores: $0=$ not tender/juicy, dislike flavor/texture/overall extremely; $50=$ neither tough nor tender, dry nor juicy, or neither like or dislike flavor/texture/overall; and 100 = very tender/juicy, like flavor/texture/overall extremely.

${ }^{2}$ Treatment lean content presented as percent lean/percent fat.

${ }^{3} \mathrm{CAB}=$ Certified Angus Beef.

${ }^{4}$ Pooled SE of the least squares means.

served among treatments during blind testing for all palatability traits. For tenderness, 90/10 ground beef rated lower $(P<0.05)$ than all other treatments, with no difference $(P>0.05)$ observed among the other 5 treatments. Both $90 / 10$ ground beef and 90/10 CAB ground sirloin were rated lower $(P<0.05)$ than all treatments other than $80 / 20 \mathrm{CAB}$ ground chuck for juiciness. Both $90 / 10$ ground beef treatments $(90 / 10$ $\mathrm{CAB}$ ground sirloin and 90/10 ground beef) were considered "dry" by consumers when blind tested, with an average rating of less than $50(50=$ neither dry nor juicy) on the 100-point scale. No differences $(P$ $>0.05$ ) were observed for texture liking, flavor liking, or overall liking among treatments when blind tested.

However, when treatment was revealed to consumers, large differences between treatments were observed. During blind testing, 90/10 CAB ground sirloin was rated more tender $(P<0.05)$ than only 90/10 ground beef and similar $(P>0.05)$ to all other treatments for tenderness. However, when product type was informed, 90/10 CAB ground sirloin rated greater $(P<0.05)$ than all other treatments for tenderness. Juiciness was rated lower $(P<0.05)$ for $90 / 10$ ground beef than all products besides $80 / 20$ ground chuck when consumers were informed of the treatment. Additionally, juiciness for 90/10 CAB ground sirloin was rated lower $(P<0.05)$ than $80 / 20$ ground beef, 80/20 ground chuck, and 73/27 $\mathrm{CAB}$ ground beef for blind testing but rated similar $(P>0.05)$ to these products during informed testing. Flavor liking, texture liking, and overall liking were all rated the highest $(P<0.05)$ for $90 / 10 \mathrm{CAB}$ ground sirloin during informed testing whereas no differences were found among treatments during blind evaluation. Also, 90/10 CAB ground sirloin was rated greater $(P<0.05)$ than $90 / 10$ ground beef in all palatability traits during informed testing, compared with only rating greater in tenderness during blind testing.

When informed of the treatment, consumer palatability ratings increased ((consumer informed score - consumer blind score)/consumer blind score) for multiple traits (Fig. 1). Very large increases $(P<0.05)$ were found for 90/10 CAB ground sirloin in tenderness (17.4\%), juiciness (36.5\%), flavor liking (23.3\%), texture liking $(18.2 \%)$, and overall liking $(24.7 \%)$. Similar increases $(P<0.05)$ were found for $80 / 20$ $\mathrm{CAB}$ ground chuck with juiciness increasing $18.6 \%$, flavor liking increasing $22.4 \%$, and overall liking increasing by $11.5 \%$ when treatment was informed. The only non-CAB-branded product to change in sensory traits was $90 / 10$ ground beef, with increased $(P<0.05)$ tenderness $(13.8 \%)$ and juiciness $(18.9 \%)$ ratings. The change in flavor liking scores for $90 / 10 \mathrm{CAB}$ ground sirloin and 80/20 CAB ground chuck were greater $(P$ $<0.05)$ than all other products tested. Furthermore, 90/10 CAB ground sirloin samples also had a greater 

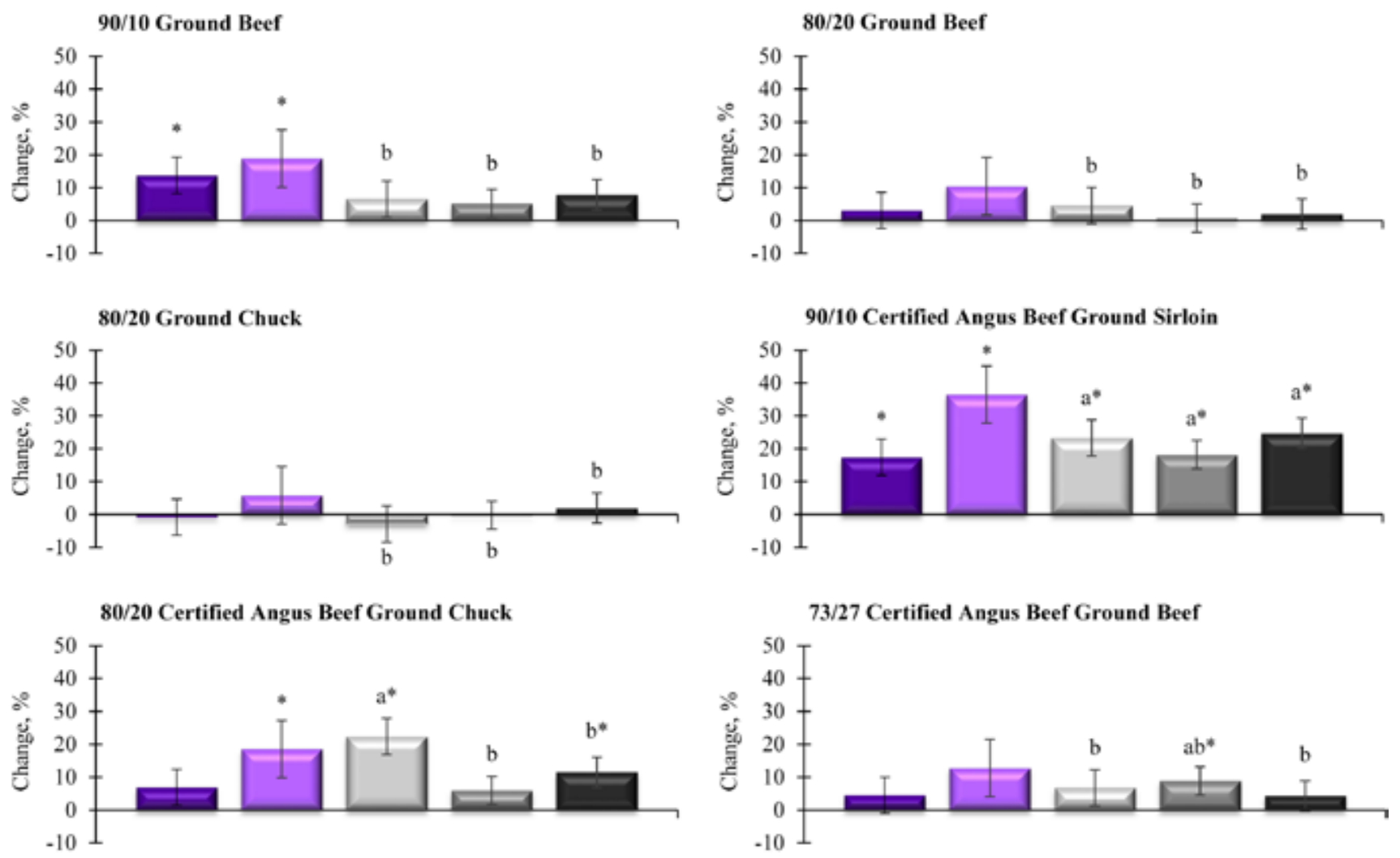

Treatment Effect

Tenderness; $P=0.16 \square$ Juiciness; $P=0.07 \quad \square$ Flavor Liking; $P<0.01$

Texture Liking; $P=0.04 \quad$ Overall Liking; $P<0.01$

Figure 1. Percentage change [(consumer informed score - consumer blind score)/consumer blind score] in consumer $(n=112)$ ratings of palatability traits due to brand disclosure before sample evaluation. Treatment lean content presented as percent lean/percent fat. *The mean differs from $0(P<0.05)$. ${ }^{\mathrm{a}, \mathrm{b}}$ Treatment means for the same palatability trait without a common superscript differ $(P<0.05)$.

$(P<0.05)$ change in texture liking scores than all treatments, except $73 / 27 \mathrm{CAB}$ ground beef. Additionally, overall liking scores increased $(P<0.05)$ the most for 90/10 CAB ground sirloin samples.

\section{Sensory Traits Rated Acceptable by Consumers}

The results for the percentage of samples rated as acceptable for palatability traits were consistent with sensory ratings (Table 6). The percentage of samples rated acceptable for tenderness was the lowest $(P<$ $0.05)$ for $90 / 10$ ground beef, with no differences $(P$ $>0.05)$ found among any of the other treatments when samples were blind tested. For juiciness, 80/20 ground beef, 80/20 ground chuck, and 73/27 CAB ground beef had more $(P<0.05)$ samples rated acceptable than both $90 / 10$ treatments. No difference $(P$ $>0.05)$ in the percentage of samples rated acceptable for flavor, texture, or overall liking were found during blind testing. However, during informed testing, 90/10 ground beef had fewer $(P<0.05)$ samples rated acceptable for tenderness than both $90 / 10 \mathrm{CAB}$ ground sirloin and 73/27 CAB ground beef. All 80/20 ground beef treatments had a similar $(P>0.05)$ percentage of samples considered acceptable for tenderness, juiciness, and texture when informed of the brand. Also, more $(P<0.05)$ 90/10 CAB ground sirloin samples were considered acceptable for texture compared with all products other than $73 / 27 \mathrm{CAB}$ ground beef.

The change in the percentage of samples rated acceptable for each palatability trait due to treatment disclosure was calculated similar to the methods described for palatability ratings. The 90/10 CAB ground sirloin had an increased $(P<0.05)$ percentage of samples rated acceptable for juiciness (20.9\%), flavor (18.2\%), texture $(18.0 \%)$, and overall acceptability $(13.5 \%)$ due to treatment disclosure (Fig. 2). Additionally, 80/20 CAB ground chuck had $11.0 \%$ more $(P<0.05)$ samples rated as acceptable for juiciness, $13.0 \%$ more for flavor, and $16.2 \%$ more rated acceptable overall. Also, there were $11.8 \%$ more $(P<0.05) 73 / 27$ CAB samples rated acceptable overall due to treatment disclosure. Under informed testing, the only commodity product that had more ( $P$ $<0.05$ ) samples rated as acceptable when compared with blind testing was 90/10 ground beef in tenderness $(8.3 \%)$. There was a greater $(P<0.05)$ change in the per- 
Table 6. Percentage of ground beef patties of varying treatments considered acceptable for tenderness, juiciness, flavor, tenderness, texture, and overall liking by consumers $(n=112)$

\begin{tabular}{|c|c|c|c|c|c|}
\hline Treatment $^{1}$ & $\begin{array}{c}\text { Tenderness } \\
\text { acceptability }\end{array}$ & $\begin{array}{c}\text { Juiciness } \\
\text { acceptability }\end{array}$ & $\begin{array}{c}\text { Flavor } \\
\text { acceptability }\end{array}$ & $\begin{array}{c}\text { Texture } \\
\text { acceptability }\end{array}$ & $\begin{array}{l}\text { Overall liking } \\
\text { acceptability }\end{array}$ \\
\hline \multicolumn{6}{|l|}{ Blind testing } \\
\hline $90 / 10$ ground beef & $72.7^{\mathrm{b}}$ & $63.1^{\mathrm{b}}$ & 76.0 & 80.5 & 74.1 \\
\hline $90 / 10 \mathrm{CAB}^{2}$ ground sirloin & $87.3^{\mathrm{a}}$ & $63.1^{\mathrm{b}}$ & 77.8 & 79.6 & 81.4 \\
\hline $80 / 20$ ground beef & $86.4^{\mathrm{a}}$ & $78.7^{\mathrm{a}}$ & 83.4 & 81.4 & 83.1 \\
\hline $80 / 20$ ground chuck & $89.8^{\mathrm{a}}$ & $77.4^{\mathrm{a}}$ & 82.3 & 86.2 & 79.4 \\
\hline 80/20 CAB ground chuck & $85.3^{\mathrm{a}}$ & $69.0^{\mathrm{ab}}$ & 72.6 & 81.9 & 72.0 \\
\hline 73/27 CAB ground beef & $85.5^{\mathrm{a}}$ & $80.5^{\mathrm{a}}$ & 79.9 & 84.9 & 77.8 \\
\hline SEM $^{3}$ & 4.3 & 5.4 & 5.4 & 4.8 & 5.0 \\
\hline$P$-value & 0.02 & 0.01 & 0.41 & 0.77 & 0.35 \\
\hline \multicolumn{6}{|l|}{ Informed testing } \\
\hline $90 / 10$ ground beef & $82.2^{\mathrm{c}}$ & $64.6^{\mathrm{c}}$ & 80.6 & $82.4^{\mathrm{c}}$ & 81.4 \\
\hline 90/10 CAB ground sirloin & $95.7^{\mathrm{a}}$ & $82.9^{\mathrm{ab}}$ & 94.0 & $96.8^{\mathrm{a}}$ & 94.9 \\
\hline $80 / 20$ ground beef & $86.9^{\mathrm{bc}}$ & $83.6^{\mathrm{ab}}$ & 82.4 & $82.3^{\mathrm{c}}$ & 82.5 \\
\hline $80 / 20$ ground chuck & $87.7^{\mathrm{bc}}$ & $77.3^{\mathrm{b}}$ & 84.0 & $84.0^{\mathrm{c}}$ & 86.9 \\
\hline 80/20 CAB ground chuck & $89.6^{\mathrm{abc}}$ & $79.3^{\mathrm{b}}$ & 86.0 & $89.3^{b c}$ & 87.9 \\
\hline 73/27 CAB ground beef & $93.9^{\mathrm{ab}}$ & $90.0^{\mathrm{a}}$ & 83.2 & $92.6^{\mathrm{ab}}$ & 89.5 \\
\hline SEM $^{3}$ & 4.1 & 4.6 & 4.2 & 4.5 & 4.3 \\
\hline$P$-value & 0.03 & $<0.01$ & 0.11 & 0.01 & 0.06 \\
\hline
\end{tabular}

centage of samples rated acceptable of flavor for $90 / 10$ CAB ground sirloin and 80/20 CAB ground chuck when tested informed compared with 80/20 ground beef. Also, the change in the percentage of samples rated acceptable for texture was greater $(P<0.05)$ for $90 / 10 \mathrm{CAB}$ ground sirloin compared with all non-CAB-branded products.

\section{Perceived Quality of Ground Beef}

All treatments had a similar $(P>0.05)$ percentage of samples rated as each of the 4 perceived quality levels when evaluated under blind conditions (Table 7). For each treatment, close to half (45.5-50.0\%) of the samples were considered "everyday" quality during blind testing. When product type and brand was informed to consumers, fewer $(P<0.05) 90 / 10 \mathrm{CAB}$ ground sirloin samples were rated as "everyday" quality than all other treatments. Also, more $(P<0.05) 90 / 10 \mathrm{CAB}$ ground sirloin samples were considered "better than everyday" and "premium" quality than all other products tested when consumers were informed of the treatment.

The perceived quality level of multiple treatments was affected by disclosure of treatment during informed testing (Fig. 3). When consumers were informed of the treatments, $13.5 \%$ fewer $(P<0.05) 90 / 10 \mathrm{CAB}$ ground sirloin and $10.8 \%$ fewer $(P<0.05) 80 / 20 \mathrm{CAB}$ ground chuck samples were rated as "unsatisfactory" quality. Consumers considered $23.1 \%$ fewer $(P<0.05)$ 90/10
CAB ground sirloin samples to be "everyday quality" during informed testing. Four of the products, both $90 / 10$ and $80 / 20$ ground beef and $90 / 10$ and $80 / 20$ CAB treatments, had a greater $(P<0.05)$ percentage $(>11.7 \%)$ of samples considered "better than everyday" quality when informed of the treatment. More $(P$ $<0.05)$ 90/10 CAB samples were rated as "premium quality" whereas fewer $(P<0.05) 80 / 20$ ground beef samples were perceived to be "premium quality" due to treatment knowledge. The 90/10 CAB ground sirloin product had a greater $(P<0.05)$ decrease in the percentage of samples rated as "everyday" quality than all treatments other than 90/10 ground beef. The greatest $(P<0.05)$ positive increase in "premium" quality was also observed for 90/10 CAB ground sirloin.

\section{Objective Measurements and Consumer Panel Relationships}

Correlations between sensory traits during blind and informed testing revealed associations that changed when consumers were informed of the brand and product type (Table 8 ). All palatability traits were highly correlated $(P<0.01)$ during both blind and informed sessions, but the associations increased in informed evaluations. Overall liking had the highest correlation $(P<0.01)$ to flavor liking $(r=0.88)$ during blind testing, whereas the highest correlation $(P$ 

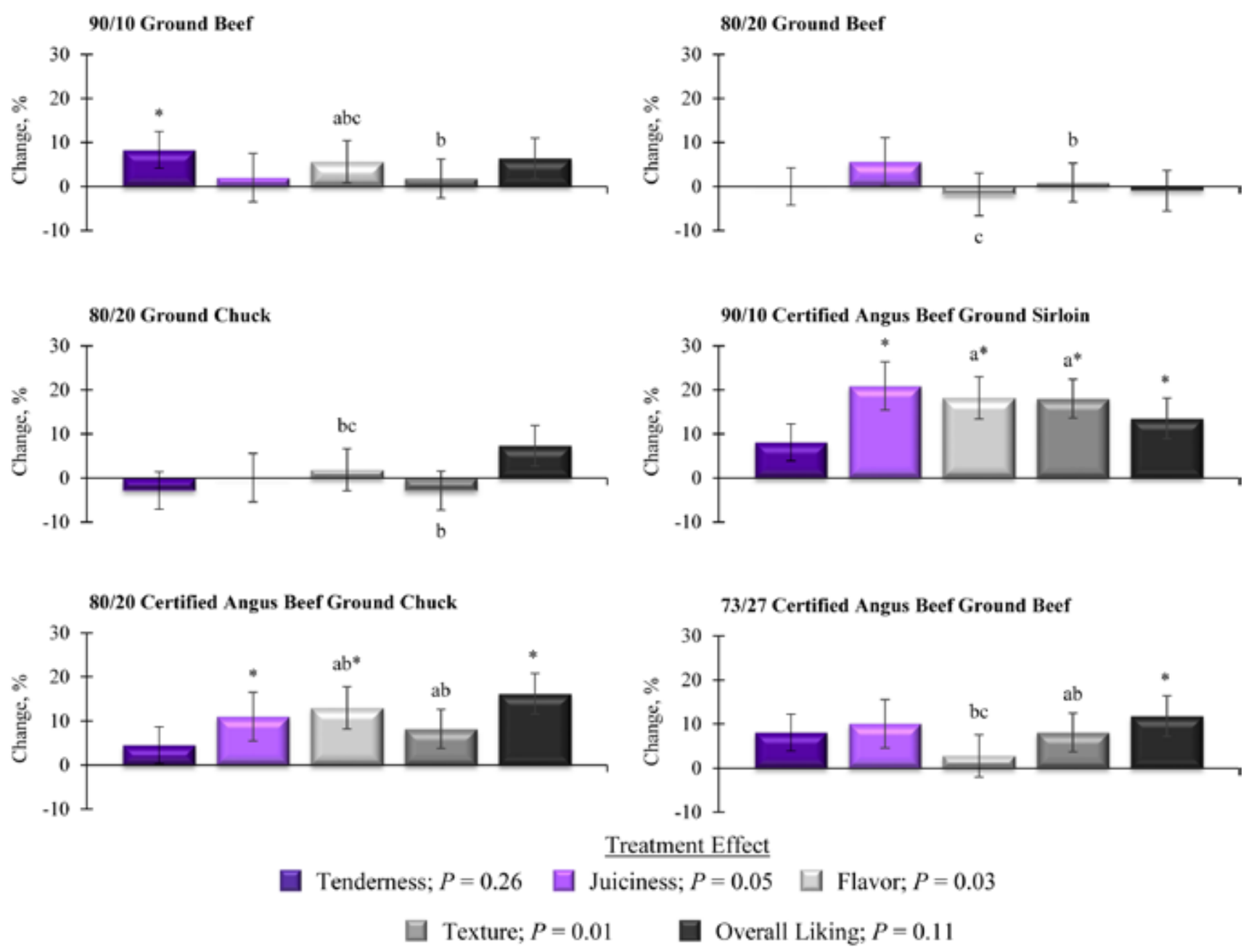

Figure 2. Change in the percentage of beef strip steaks of varying quality treatments considered acceptable for tenderness, juiciness, flavor, texture, and overall liking by consumers $(n=112)$ due to brand disclosure before sample evaluation. Treatment lean content presented as percent lean/percent fat. *The mean differs from $0(P<0.05) .{ }^{\text {a-c }}$ Treatment means for the same trait without a common superscript differ $(P<0.05)$.

$<0.01$ ) for overall liking was observed with texture liking $(r=0.86)$ when consumers were informed of the treatment. Fat and moisture were both correlated $(P<0.01)$ with juiciness in blind testing $(r=0.32$ and $r=-0.29$, respectively); however, when treatment was disclosed, juiciness was no longer correlated $(P>$ 0.05 ) with fat percentage. Conversely, in blind testing, there was no $(P>0.05)$ relationship between fat content and flavor liking, texture liking, or overall liking scores; however, during informed testing, all 3 were associated $(P<0.05)$ with fat percentage $(r=-0.29$ to $-0.25)$. Shear force was correlated $(P<0.05)$ to only tenderness $(r=-0.20)$ in blind testing, but during informed testing, shear force was negatively associated $(P<0.05)$ with tenderness $(r=-0.40)$, juiciness $(r$ $=-0.29)$, flavor liking $(r=-0.25)$, texture liking $(r=$ $-0.32)$, and overall liking $(r=-0.26)$. Fat and moisture percentage were related $(P<0.05)$ to shear force values at $r=-0.23$ and $r=0.24$, respectively.

Table 9 presents the relationships between texture profile analysis and ground beef sensory traits. During blind testing, tenderness was correlated $(P<0.01)$ to hardness $(r=-0.31)$, cohesiveness $(r=-0.35)$, gumminess $(r=-0.33)$, and chewiness $(r=-0.29)$. However, tenderness was not $(P>0.05)$ correlated to any texture traits when consumers were informed of the treatment. Gumminess was the only texture trait correlated $(P<0.05)$ to overall liking in blind testing, but this relationship was not seen during informed sampling. Also, it is noteworthy that consumer texture liking had no relationship $(P>0.05)$ with any of the objective measures for texture in this study.

\section{DISCUSSION}

\section{Proximate Measurements}

For most treatments in the current study, the observed fat percentage was slightly lower than the identified, labeled fat percentage formulated by the supplier. The lower measured fat percentage could be due to differences in methodology used for fat measurement. Most commercial ground beef manufacturers use near-infrared spectroscopy to determine the fat percentages of beef 
Table 7. Percentage of ground beef patties of varying treatments categorized by perceived eating quality level by consumers $(n=112)$

\begin{tabular}{|c|c|c|c|c|}
\hline Treatment $^{1}$ & $\begin{array}{c}\text { Unsatisfactory } \\
\text { quality }\end{array}$ & $\begin{array}{c}\text { Everyday } \\
\text { quality }\end{array}$ & $\begin{array}{c}\text { Better than } \\
\text { everyday quality }\end{array}$ & $\begin{array}{c}\text { Premium } \\
\text { quality }\end{array}$ \\
\hline \multicolumn{5}{|l|}{ Blind testing } \\
\hline $90 / 10$ ground beef & 20.0 & 50.0 & 22.7 & 6.2 \\
\hline 90/10 $\mathrm{CAB}^{2}$ ground sirloin & 16.4 & 45.5 & 32.7 & 4.6 \\
\hline $80 / 20$ commodity ground beef & 14.5 & 49.1 & 20.0 & 14.4 \\
\hline $80 / 20$ commodity ground chuck & 16.5 & 43.1 & 32.1 & 7.1 \\
\hline 80/20 CAB ground chuck & 20.2 & 47.7 & 22.9 & 7.9 \\
\hline $73 / 27 \mathrm{CAB}$ ground beef & 14.5 & 46.4 & 31.8 & 6.2 \\
\hline SEM $^{3}$ & 3.9 & 4.8 & 4.5 & 4.4 \\
\hline$P$-value & 0.78 & 0.92 & 0.12 & 0.10 \\
\hline \multicolumn{5}{|l|}{ Informed testing } \\
\hline $90 / 10$ ground beef & 17.0 & $40.3^{\mathrm{a}}$ & $36.9^{\mathrm{b}}$ & $6.2^{\mathrm{b}}$ \\
\hline 90/10 CAB ground sirloin & 2.7 & $22.8^{\mathrm{b}}$ & $51.4^{\mathrm{a}}$ & $23.2^{\mathrm{a}}$ \\
\hline $80 / 20$ ground beef & 9.0 & $49.9^{\mathrm{a}}$ & $34.6^{\mathrm{b}}$ & $7.2^{b}$ \\
\hline $80 / 20$ ground chuck & 10.9 & $49.9^{\mathrm{a}}$ & $34.6^{\mathrm{b}}$ & $5.4^{\mathrm{b}}$ \\
\hline 80/20 CAB ground chuck & 9.9 & $46.7^{\mathrm{a}}$ & $34.2^{\mathrm{b}}$ & $9.8^{\mathrm{b}}$ \\
\hline $73 / 27 \mathrm{CAB}$ ground beef & 9.0 & $53.6^{\mathrm{a}}$ & $29.1^{\mathrm{b}}$ & $9.0^{\mathrm{b}}$ \\
\hline SEM $^{3}$ & 3.7 & 5.5 & 4.7 & 4.3 \\
\hline$P$-value & 0.05 & $<0.01$ & 0.03 & $<0.01$ \\
\hline
\end{tabular}

grinds and formulate to targeted fat percentages using these numbers. Studies that have compared fat percentages of beef samples using multiple analytical methods have reported CEM methodology, similar to that used in the current study, to estimate fat percentages of beef lower than other techniques (Dow et al., 2011). Additionally, studies that have evaluated the fat percentages from strip loin steaks using CEM methods (Hoelscher et al., 1988; Dow et al., 2011; Dikeman et al., 2013) have consistently reported means lower than authors who have evaluated the fat percentages of strip loin steaks of the same quality grades using near-infrared spectroscopy (O'Quinn et al., 2012; Hunt et al., 2014; Corbin et al., 2015).

\section{Objective Texture Measurement and Shear Values}

Texture profile analysis has been reported by other authors for ground beef patties using equations and calculations from Bourne (1978). Troutt et al. (1992a) and Troutt et al. (1992b) demonstrated that lower fat formulations had increased hardness values using a texture profile analysis method similar to that in the current study. Fat level has been reported to affect other textural values, with increased fat level resulting in lower cohesiveness, gumminess, and chewiness values, with little impact on springiness, as fat increased from 4 to 20\% (Berry, 1994). These trends for textural properties and increased fat level were demonstrated in the current study as well with samples formulated to have fat percentages ranging from 10 to $27 \%$. In the current study, texture measurements of hardness, cohesiveness, gumminess, and chewiness were reported to be correlated with consumer tenderness and juiciness ratings in blind evaluations, but instrumental texture measurements had no relationship with consumer texture liking scores. Other authors have reported correlations close to $r=0.50$ for ground beef hardness, springiness, and cohesiveness values and trained panel firmness ratings (Troutt et al., 1992b), although other reported associations between ground beef texture profile analysis and consumer texture evaluations are lacking. Results of our study indicate texture profile analysis may not be representative of consumer texture liking of ground beef patties.

The shear values in the current study were affected by fat level similar to texture measurements. The 90/10 ground beef had the highest shear value, which was $28 \%$ higher than that of $73 / 27 \mathrm{CAB}$ ground beef. A trend of decreasing fat percentage and increasing shear force values has been well documented by many authors using ground beef spanning a wider range than that of the current study (Berry and Leddy, 1984; Troutt et al., 1992a,b; Desmond et al., 1998). Ground beef shear force values have also been reported to be correlated ( $r=-0.22$ to -0.72 ) to trained sensory panel tenderness values (Troutt et al., 1992b; Desmond et al., 1998; Highfill, 2012; McHenry, 2013). In the current study, shear force values were found to have 

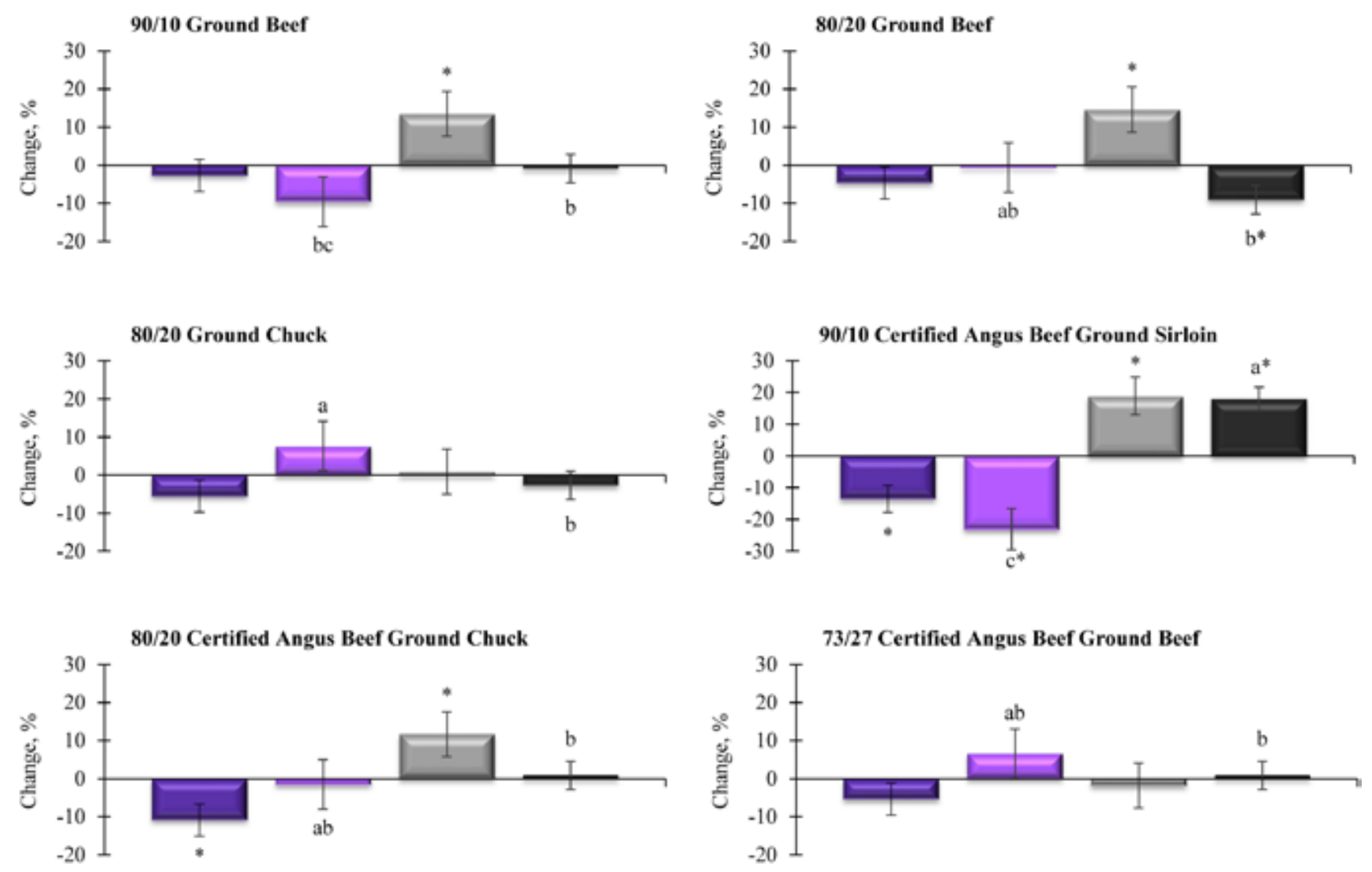

Treatment Effect

$$
\text { Unsatisfactory; } P=0.43 \square \text { Everyday; } P<0.01
$$

Better than Everyday; $P=0.08$

Premium; $P<0.01$

Figure 3. Change in the percentage of beef strip steaks of varying treatments categorized into perceived eating quality levels by consumers $(n=$ $112)$ due to brand disclosure before sample evaluation. Treatment lean content presented as percent lean/percent fat. $*$ The mean differs from $0(\mathrm{P}<0.05)$. ${ }^{\mathrm{a}-\mathrm{c}}$ Treatment means for the same quality level without a common superscript differ $(P<0.05)$.

a relationship with consumer tenderness ratings during blind evaluations. Additionally, this association between shear force and tenderness ratings strengthened as a result of brand disclosure, potentially due to the increase in tenderness ratings for the 90/10 CAB ground sirloin treatment and the low shear force value associated with this treatment. Nevertheless, these results suggest ground beef shear force values are not only an indicator of trained panel tenderness ratings but of consumer tenderness ratings as well.

\section{Consumer Purchasing Motivators}

Purchasing motivators have been evaluated by many authors to gain insight into how consumers select and evaluate meat during the retail shopping process. In our study, consumers placed greater importance on product intrinsic traits such as color, size, and marbling than on attributes such as brand and animal production claims. Similarly, other authors have demonstrated that visual quality cues to be of high importance to consumers when purchasing products (Steenkamp and vanTrijp, 1996; Wachenheim et al., 2000; Grunert et al., 2004). The large exception to this trend is price, an extrinsic factor, which was determined to be one of the most important traits to consumers when purchasing beef in the current study as well as many others (Claborn et al., 2011; Reicks et al., 2011; Lucherk et al., 2016). Although productionrelated information was among the lowest rated traits for importance in the current study, many authors have demonstrated its importance to the acceptance of and value consumers place on beef products (Grannis et al., 2000; Mennecke et al., 2007; Grunert et al., 2011).

\section{Effect of Fat Level on Palatability Ratings of Ground Beef}

Few differences in consumer ratings of ground beef with various fat percentages were found for tenderness, flavor liking, texture liking, and overall liking during blind testing. However, juiciness was shown to be effected by fat level, with the two 90/10 treatments rating lower than 3 of the higher fat products when blind tested. Although the current study demonstrated few differences during blind testing of ground beef patties varying in fat level, previous authors have reported differences in multiple palatability traits. Higher- 
Table 8. Pearson correlation coefficients among consumer panel sensory scores, proximate composition, and shear force of ground beef

\begin{tabular}{|c|c|c|c|c|c|c|c|c|c|}
\hline Traits & Tenderness & Juiciness & $\begin{array}{l}\text { Flavor } \\
\text { liking }\end{array}$ & $\begin{array}{l}\text { Texture } \\
\text { liking }\end{array}$ & $\begin{array}{l}\text { Overall } \\
\text { liking }\end{array}$ & $\begin{array}{l}\text { Shear } \\
\text { force }\end{array}$ & Moisture & Protein & Fat \\
\hline \multicolumn{10}{|l|}{ Blind testing } \\
\hline Juiciness & $0.62 * *$ & & & & & & & & \\
\hline Flavor liking & $0.56^{* *}$ & $0.60 * *$ & & & & & & & \\
\hline Texture liking & $0.58 * *$ & $0.45^{* *}$ & $0.71 * *$ & & & & & & \\
\hline Overall liking & $0.65 * *$ & $0.67 * *$ & $0.88 * *$ & $0.81 * *$ & & & & & \\
\hline Shear force & $-0.20 *$ & -0.07 & -0.02 & -0.10 & -0.08 & & & & \\
\hline Moisture & -0.17 & $-0.29 * *$ & 0.01 & 0.03 & -0.07 & $0.24 *$ & & & \\
\hline Protein & -0.06 & -0.01 & 0.01 & -0.10 & -0.01 & $0.21 *$ & $0.34 * *$ & & \\
\hline Fat & 0.18 & $0.32 * *$ & -0.02 & -0.02 & 0.07 & $-0.23^{*}$ & $-0.83^{* *}$ & $-0.42 * *$ & \\
\hline Ash & -0.06 & $-0.22 *$ & -0.02 & 0.05 & -0.06 & -0.19 & $0.39 * *$ & 0.20 & $-0.55^{* *}$ \\
\hline \multicolumn{10}{|l|}{ Informed testing } \\
\hline Juiciness & $0.72 * *$ & & & & & & & & \\
\hline Flavor liking & $0.66^{* *}$ & $0.59 * *$ & & & & & & & \\
\hline Texture liking & $0.81 * *$ & $0.59 * *$ & $0.73 * *$ & & & & & & \\
\hline Overall liking & $0.78 * *$ & $0.61^{* *}$ & $0.85^{* *}$ & $0.86^{* *}$ & & & & & \\
\hline Shear force & $-0.40 * *$ & $-0.29 * *$ & $-0.25^{*}$ & $-0.32 * *$ & $-0.26^{*}$ & & & & \\
\hline Moisture & 0.02 & $-0.26^{* *}$ & 0.19 & 0.18 & 0.17 & & & & \\
\hline Protein & -0.10 & -0.11 & 0.11 & 0.03 & 0.14 & & & & \\
\hline Fat & -0.05 & 0.19 & $-0.29 * *$ & $-0.25^{*}$ & $-0.27 * *$ & & & & \\
\hline Ash & 0.15 & -0.07 & $0.32 * *$ & $0.37 * *$ & $0.34 * *$ & & & & \\
\hline
\end{tabular}

fat ground beef has been observed to have greater tenderness compared with lower-fat formulations (Cross et al., 1980; Berry and Leddy, 1984; Kregel et al., 1986; Garzon et al., 2003). Also, similar to the current study, ground beef with higher fat has been well documented as having higher juiciness ratings than low-fat ground beef (Cross et al., 1980; Huffman and Egbert, 1990; Miller et al., 1993; Blackmon et al., 2015). Additionally, others have found no difference in ground beef patties for sensory texture ratings across samples with fat percentages similar to those used in the current study (Kendall et al., 1974; Desmond et al., 1998). However, all of these cited studies have used trained sensory panelists in comparison with the consumers used in the current study. Very few studies have used consumer panelists to evaluate ground beef palatability. This difference in methodology (trained vs. consumer sensory panels) likely contributed to the differences in results between the current study and previous reports. Unlike previous work with trained sensory panelists, our results indicate that no differences exist for ground beef flavor, texture, or overall liking, with only limited differences in tenderness and juiciness of ground beef ranging from 10 to $27 \%$ fat when blind evaluated by consumers.

The 90/10 CAB ground sirloin had increased ratings for every palatability trait as well as an increased percentage of samples rated acceptable for all traits except tenderness due to treatment disclosure. Additionally, a clear shift occurred in the perceived quality level of these samples from "unsatisfactory" and "everyday" quality to "better than everyday" and "premium" quality. The reason for this large increase in eating quality as a result of treatment disclosure may be the attributed to many of the product's characteristics. It is well documented that consumers identify ground beef with lower fat percentages as higher quality and they are willing pay premiums for these products (Lusk and Parker, 2009; USDA, 2016). This is also supported by the current study. During blind evaluation, no relationship was found between fat percentage and flavor, texture, and overall liking, with fat percentage positively associated with juiciness. However, when consumers were informed of the fat percentage prior to testing, fat content had a negative correlation $(r=-0.29$ to -0.25$)$ with flavor, texture, and overall liking scores and the positive relationship between fat percentage and juiciness was no longer found. These results give clear evidence that when consumers were informed of the sample's fat percentage prior to evaluation, higher fat content had a negative impact on eating quality.

When comparing the 2 commodity ground beef treatments differing in fat level $(90 / 10$ ground beef and $80 / 20$ ground beef), only the $90 / 10$ ground beef received a "lift" in palatability due to treatment disclosure. Both tenderness and juiciness increased due 
Table 9. Pearson correlation coefficients among consumer panel sensory scores and texture profile analysis measurements

\begin{tabular}{|c|c|c|c|c|c|}
\hline Trait & Hardness & Cohesiveness & Springiness & Gumminess & Chewiness \\
\hline \multicolumn{6}{|l|}{ Blind testing } \\
\hline Tenderness & $-0.31 * *$ & $-0.35 * *$ & 0.15 & $-0.33 * *$ & $-0.29 * *$ \\
\hline Juiciness & $-0.34 * *$ & $-0.48 * *$ & -0.13 & $-0.40^{* *}$ & $-0.42 * *$ \\
\hline Flavor liking & -0.11 & -0.09 & 0.04 & -0.11 & -0.10 \\
\hline Texture liking & -0.08 & -0.12 & 0.05 & -0.08 & -0.07 \\
\hline Overall liking & -0.23 & -0.22 & 0.00 & $-0.24 *$ & -0.23 \\
\hline \multicolumn{6}{|c|}{ Informed testing } \\
\hline Tenderness & -0.13 & 0.00 & 0.04 & -0.10 & 0.08 \\
\hline Juiciness & $-0.36^{* *}$ & $-0.24 *$ & -0.19 & $-0.35^{* *}$ & $-0.37 * *$ \\
\hline Flavor liking & 0.15 & 0.06 & -0.01 & 0.14 & 0.14 \\
\hline Texture liking & -0.02 & 0.03 & 0.07 & 0.00 & 0.03 \\
\hline Overall liking & 0.01 & 0.06 & 0.05 & 0.03 & 0.05 \\
\hline
\end{tabular}

to treatment disclosure for the $90 / 10$ ground beef, with no changes in ratings for any palatability factors for the $80 / 20$ ground beef, indicating that the leaner product more positively influenced consumer perception of eating quality. A consumer survey by Lusk and Parker (2009) supports our findings and indicates that consumers consider $90 / 10$ ground beef higher quality than $80 / 20$ ground beef and are willing to pay $\$ 2.00$ more for the reduced-fat product.

As beef prices have increased, retailers have often used ground beef as an affordably priced beef alternative to more inexpensive proteins including pork and chicken (Speer et al., 2015). In this way, ground beef offers budget-conscious consumers a competitively priced beef item as an alternative to premium priced beef items, including steaks. It is noteworthy that in the current study, more than half of the consumer panelists had an average household income of over $\$ 75,000$. The impact of income level on consumer perception of ground beef branding and product identification is unclear. However, branded products and ground beef with lower fat percentages are marketed at higher prices (USDA, 2016). When interpreting the results of the current study, it is important to consider the demographic profile of the consumer panelists and the potential influence this may have had on their product evaluations.

\section{Subprimal Effect on Palatability Ratings of Ground Beef}

Recently, an increased number of studies have evaluated the characteristics of subprimal and primalspecific sourced blends in an effort to gain a better of understanding of ground beef palatability as a result of increased demand for ground beef products. Researchers have evaluated multiple factors, including the effect of fat source (Blackmon et al., 2015; Kerth et al., 2015), marbling and maturity levels (Highfill, 2012; Myers, 2012), and muscle-specific and subprimal-specific blends (Fruin and Van Duyne, 1961; Nielsen et al., 1967; Highfill, 2012; McHenry, 2013; Tigue, 2013). Much of this research has demonstrated results similar to those of the current study, with very few differences among primal/subprimal/musclespecific sourced blends for palatability characteristics. Within these studies, fat and lean source played only a minimal role in palatability of ground beef. However, McHenry (2013) reported that ground beef patties from the chuck were more desirable in flavor attributes compared with ground beef from the brisket and sirloin cap when evaluated by trained panelists. In the current study, no differences were found between the $80 / 20$ ground chuck and 80/20 ground beef samples for all traits evaluated, indicating that previously reported flavor-related advantages of ground chuck by trained sensory panelists were not detected by our consumer panelists.

Moreover, when consumers were informed of primal blend, palatability ratings for $80 / 20$ ground chuck samples remained unaffected, similar to ratings for the $80 / 20$ ground beef. However, the same was not observed for the two $90 / 10$ products. When treatments were disclosed, the $90 / 10 \mathrm{CAB}$ ground sirloin rated greater than the $90 / 10$ ground beef for every palatability trait tested, whereas when blind tested, 90/10 CAB ground sirloin was rated higher only for tenderness. This demonstrates that consumers placed no additional significance on chuck-specific branding over commodity branding; however, sirloin-specific ground beef did receive a palatability advantage related to branding. The extent to which the observed increases in palatability ratings for the $90 / 10 \mathrm{CAB}$ ground sir- 
loin that were directly related to sirloin branding are unclear, as the current study did not include a 90/10 commodity ground sirloin for comparison.

\section{Effect of Branding on Consumer Palatability Ratings of Ground Beef}

All 3 of the CAB-branded products received increased ratings for palatability traits when consumers were informed of the brand prior to evaluation, indicating that these products received a "brand lift" in palatability due to $\mathrm{CAB}$ branding. As previously discussed, the palatability ratings for commodity $80 / 20$ ground chuck were unaffected by treatment disclosure. However, the same was not observed for $80 / 20$ CAB ground chuck, which had increased ratings for juiciness, flavor liking, and overall liking when consumers were informed of the brand. Also, a shift in the perceived quality level of this product was observed, as fewer samples were rated "unacceptable" and a greater percentage rated as "better than everyday quality." Despite the negative consumer perception of the higher fat content, 73/27 CAB ground beef had increased ratings for texture liking as well as a greater percentage of samples rated acceptable overall when consumers were informed of the brand. It is noteworthy that all 3 of the CAB-branded products increased (11.8 to $16.2 \%$ ) in the percentage of samples rated acceptable overall due to brand disclosure. Although it is unclear the exact proportion of the observed increases in palatability ratings observed for the 90/10 CAB ground sirloin that were associated with both lean content and sirloin branding, results from the other 2 CABbranded products indicate that some of the observed "brand lift" was a result of CAB branding.

Banović et al. (2009) noted that brand is one of the most important indicators of product quality in beef. Similar to the current study, disclosing brand and product information has been reported to have an effect on many other products when evaluated by consumers. A recent study reported that $\mathrm{CAB}$ and "Angus" branding resulted in increased consumer ratings $(10-16 \%)$ for beef strip loin steaks (Wilfong et al., 2016). The same study found that USDA Choice and Select branding had no effect on eating quality and, much like the current study, provided evidence that branding alone does not benefit beef eating quality, only branding with brands consumers view as high quality (Wilfong et al., 2016).

The effect of branding on the palatability of other food products has been tested as well. Overall liking has been reported to increase up to $20 \%$ for well-known brands of beer, yogurt, chocolate hazelnut spreads, chicken breast meat, and spaghetti noodles (Allison and Uhl, 1964; Di Monaco et al., 2004; Kim and Lee, 2015;
Spinelli et al., 2015; Samant and Seo, 2016). Other products, including nutritional supplements, have also been reported to have increased acceptability (30\%) when consumed under informed settings compared with blind sampling (Skipper et al., 1999). However, other authors have reported no change in palatability perception when information about orange juice, biscuits, frozen sweet corn, champignons, and bottled water was disclosed prior to sample evaluation (Carrillo et al., 2012; Szőke et al., 2012; Kim and Lee, 2015).

These studies, along with current results, provide clear evidence of the impact of branding on consumer eating satisfaction. For ground beef, decreased fat level and $\mathrm{CAB}$ branding provided a palatability-related impact. These results underscore the importance of branding of ground beef products sold to consumers and indicate an opportunity for value creation in ground beef through product branding.

\section{LITERATURE CITED}

Allison, R. I., and K. P. Uhl. 1964. Influence of beer brand identification on taste perception. J. Mark. Res. 1:36-39. doi:10.2307/3150054

American Meat Science Association (AMSA). 2015. Research guidelines for cookery, sensory evaluation, and instrumental tenderness measurements of meat. 2nd ed. AMSA, Champaign, IL.

AOAC. 2005. Official methods of analysis. 18th ed. AOAC Int., Arlington, VA.

Banović, M., K. G. Grunert, M. M. Barreira, and M. A. Fontes. 2009. Beef quality perception at the point of purchase: A study from Portugal. Food Qual. Prefer. 20:335-342. doi:10.1016/j. foodqual.2009.02.009

Berry, B. W. 1992. Low fat level effects on sensory, shear, cooking, and chemical properties of ground beef patties. J. Food Sci. 57:537. doi:10.1111/j.1365-2621.1992.tb08037.x

Berry, B. W. 1994. Fat level, high temperature cooking and degree of doneness affect sensory, chemical and physical properties of beef patties. J. Food Sci. 59:10-14. doi:10.1111/j.1365-2621.1994. tb06885.x

Berry, B. W., and K. F. Leddy. 1984. Effects of fat level and cooking method on sensory and textural properties of ground beef patties. J. Food Sci. 49:870-875. doi:10.1111/j.1365-2621.1984.tb13231.x

Blackmon, T., R. K. Miller, C. Kerth, and S. B. Smith. 2015. Ground beef patties prepared from brisket, flank and plate have unique fatty acid and sensory characteristics. Meat Sci. 103:46-53. doi:10.1016/j.meatsci.2015.01.004

Bourne, M. C. 1978. Texture profile analysis. Food Technol. 32:62-67.

Bureau of Labor Statistics. 2016. Average retail food and energy prices, U.S. and Midwest region. http://www.bls.gov/regions/ mid-atlantic/data/AverageRetailFoodAndEnergyPrices USandMidwest_Table.htm. (Accessed July 20, 2016.)

Carrillo, E., P. Varela, and S. Fiszman. 2012. Effects of food package information and sensory characteristics on the perception of healthiness and the acceptability of enriched biscuits. Food Res. Int. 48:209-216. doi:10.1016/j.foodres.2012.03.016 
Claborn, S. W., A. J. Garmyn, J. C. Brooks, R. J. Rathmann, C. B. Ramsey, L. D. Thompson, and M. F. Miller. 2011. Consumer evaluation of the palatability of UDSA Select, USDA Choice, and Certified Angus Beef strip loin steaks from retail markets in Lubbock, Texas. J. Food Qual. 34:425-434. doi:10.1111/j.17454557.2011.00415.x

Corbin, C. H., T. G. O’Quinn, A. J. Garmyn, J. F. Legako, M. R. Hunt, T. T. N. Dinh, R. J. Rathmann, J. C. Brooks, and M. F. Miller. 2015. Sensory evaluation of tender beef strip loin steaks of varying marbling levels and quality treatments. Meat Sci. 100:24-31. doi:10.1016/j.meatsci.2014.09.009

Cross, H. R., B. W. Berry, and L. H. Wells. 1980. Effects of fat level and source on the chemical, sensory, and cooking properties of ground beef patties. J. Food Sci. 45:791-794. doi:10.1111/j.1365-2621.1980.tb07450.x

Desmond, E., D. Troy, and D. Buckley. 1998. Comparative studies of non-meat adjuncts used in the manufacture of low-fat ground beef burgers. J. Muscle Foods 9:221-241. doi:10.1111/j.1745-4573.1998.tb00657.x

Dikeman, M. E., E. Obuz, V. Gök, L. Akkaya, and S. Stroda. 2013. Effects of dry, vacuum, and special bag aging; USDA quality grade; and end-point temperature on yields and eating quality of beef longissimus lumborum steaks. Meat Sci. 94:228-233. doi:10.1016/j.meatsci.2013.02.002

Di Monaco, R., S. Cavella, S. Di Marzo, and P. Masi. 2004. The effect of expectations generated by brand name on the acceptability of dried semolina pasta. Food Qual. Prefer. 15:429-437. doi:10.1016/j.foodqual.2003.07.003

Dow, D. L., B. R. Wiegand, M. R. Ellersieck, and C. L. Lorenzen. 2011. Prediction of fat percentage within marbling score on beef longissimus muscle using 3 different fat determination methods. J. Anim. Sci. 89:1173-1179. doi:10.2527/jas.2010-3382

Fruin, M. F., and F. O. Van Duyne. 1961. Fat content, yield, and palatability of ground beef. J. Am. Diet. Assoc. 39:317-320.

Garzon, G., F. McKeith, J. Gooding, F. Felker, D. Palmquist, and M. Brewer. 2003. Characteristics of low-fat beef patties formulated with carbohydrate-lipid composites. J. Food Sci. 68:2050 2056. doi:10.1111/j.1365-2621.2003.tb07017.x

Grannis, J., N. H. Hooker, and D. Thilmany. 2000. Consumer preferences for specific attributes in natural beef products. Paper presented at West. Agric. Econ. Assoc. Annual Meeting, Vancouver BC, 29 June - 1 July.

Grunert, K. G., L. Bredahl, and K. Brunsø. 2004. Consumer perception of meat quality and implications for product development in the meat sector-A review. Meat Sci. 66:259-272. doi:10.1016/S0309-1740(03)00130-X

Grunert, K. G., W. Verbeke, J. O. Kügler, F. Saeed, and J. Scholderer. 2011. Use of consumer insight in the new product development process in the meat sector. Meat Sci. 89:251-258. doi:10.1016/j.meatsci.2011.04.024

Highfill, C. M. 2012. Effects of subprimal, quality grade, and aging time on display color and sensory properties of ground beef patties. MS Thesis, Kansas State University, Manhattan, KS.

Hoelscher, L., J. Savell, S. Smith, and H. Cross. 1988. Subcellular distribution of cholesterol within muscle and adipose tissues of beef loin steaks. J. Food Sci. 53:718-722. doi:10.1111/j.1365-2621.1988.tb08939.x

Huffman, D., and W. Egbert. 1990. Chemical analysis and sensory evaluation of the developed lean ground beef products. Auburn University, Auburn, AL. Alabama Agric Exp. Sta. Bull. no. 606.
Hunt, M. R., A. J. Garmyn, T. G. O'Quinn, C. H. Corbin, J. F. Legako, R. J. Rathmann, J. C. Brooks, and M. F. Miller. 2014. Consumer assessment of beef palatability from four beef muscles from USDA Choice and Select graded carcasses. Meat Sci. 98:1-8. doi:10.1016/j.meatsci.2014.04.004

Kendall, P. A., D. L. Harrison, and A. D. Dayton. 1974. Quality attributes of ground beef on the retail market. J. Food Sci. 39:610614. doi:10.1111/j.1365-2621.1974.tb02961.x

Kerth, C. R., A. L. Harbison, S. B. Smith, and R. K. Miller. 2015. Consumer sensory evaluation, fatty acid composition, and shelf-life of ground beef with subcutaneous fat trimmings from different carcass locations. Meat Sci. 104:30-36. doi:10.1016/j. meatsci.2015.01.014

Kim, M. K., and K.-G. Lee. 2015. Influences of intrinsic and extrinsic factors on consumer acceptance of orange juice using consumer liking testing and Kano analysis techniques. Food Sci. Biotechnol. 24:1687-1693. doi:10.1007/s10068-015-0219-4

Kregel, K. K., K. J. Prusa, and K. V. Hughes. 1986. Cholesterol content and sensory analysis of ground beef as influenced by fat level, heating, and storage. J. Food Sci. 51:1162-1165. doi:10.1111/j.1365-2621.1986.tb13073.x

Lucherk, L. W., T. G. O’Quinn, J. F. Legako, R. J. Rathmann, J. C. Brooks, and M. F. Miller. 2016. Consumer and trained panel evaluation of beef strip steaks of varying marbling and enhancement levels cooked to three degrees of doneness. Meat Sci. 122:145-154. doi:10.1016/j.meatsci.2016.08.005

Lusk, J. L., and N. Parker. 2009. Consumer preferences for amount and type of fat in ground beef. J. Agric. Appl. Econ. 41:75-90. doi:10.1017/S107407080000256X

McHenry, J. H. 2013. Discovering ground beef performance through "premium grind" concepts. MS Thesis, Colorado State University, Fort Collins, CO.

Mennecke, B. E., A. M. Townsend, D. J. Hayes, and S. M. Lonergan. 2007. A study of the factors that influence consumer attitudes toward beef products using the conjoint market analysis tool. J. Anim. Sci. 85:2639-2659. doi:10.2527/jas.2006-495

Miller, M., M. Andersen, C. Ramsey, and J. Reagan. 1993. Physical and sensory characteristics of low fat ground beef patties. J. Food Sci. 58:461-463. doi:10.1111/j.1365-2621.1993.tb04299.x

Myers, N. B. 2012. Evaluation of ground beef quality from commodity and premium quality trimmings. MS Thesis, University of Florida, Gainesville, FL.

National Cattlemen's Beef Association, National Pork Board, and Sealed Air Corporation. 2010. A snapshot of today's retail meat case - 2010 National Meat Case Study executive summary. National Cattlemen's Beef Association, Centennial, CO.

Nielsen, M., F. Hall, E. Monsen, and B. Worthington. 1967. Eating quality, nutritive value, and cost of ground round and hamburger. J. Am. Diet. Assoc. 50:201-203.

O'Quinn, T. G., J. C. Brooks, R. J. Polkinghorne, A. J. Garmyn, B. J. Johnson, J. D. Starkey, R. J. Rathmann, and M. F. Miller. 2012. Consumer assessment of beef strip loin steaks of varying fat levels. J. Anim. Sci. 90:626-634. doi:10.2527/jas.2011-4282

Reicks, A. L., J. C. Brooks, A. J. Garmyn, L. D. Thompson, C. L. Lyford, and M. F. Miller. 2011. Demographics and beef preferences affect consumer motivation for purchasing fresh beef steaks and roasts. Meat Sci. 87:403-411. doi:10.1016/j.meatsci. 2010.11 .018

Samant, S. S., and H.-S. Seo. 2016. Quality perception and acceptability of chicken breast meat labeled with sustainability claims vary as a function of consumers' label-understanding level. Food Qual. Prefer. 49:151-160. doi:10.1016/j. foodqual.2015.12.004 
Skipper, A., C. Bohac, and M. B. Gregoire. 1999. Knowing brand name affects patient preferences for enteral supplements. J. Acad. Nutr. Diet. 99:91-92.

Speer, N., T. Brink, and M. McCully. 2015. Changes in the ground beef market and what it means for cattle producers. The Angus Foundation, St. Joseph, MO.

Spinelli, S., C. Masi, G. Zoboli, J. Prescott, and E. Monteleone. 2015. Emotional responses to branded and unbranded foods. Food Qual. Prefer. 42:1-11. doi:10.1016/j.foodqual.2014.12.009

Steenkamp, J. B. E. M., and H. C. M. vanTrijp. 1996. Quality guidance: A consumer-based approach to food quality improvement using partial least squares. Eur. Rev. Agric. Econ. 23:195-215. doi:10.1093/erae/23.2.195

Szőke, A., V. Losó, L. Sipos, A. Geösel, A. Gere, and Z. Kókai. 2012. The effect of brand/type/variety knowledge on the sensory perception. Acta Aliment. 41:197-204. doi:10.1556/ AAlim.41.2012.Suppl.19

Tigue, D. A. 2013. An analysis of quality of non-traditional beef grind material versus traditional beef grind material for ground beef products. MS Thesis, Auburn University, Auburn, AL.
Troutt, E. S., M. C. Hunt, D. E. Johnson, J. R. Claus, C. L. Kastner, and D. H. Kropf. 1992a. Characteristics of low-fat ground beef containing texture-modifying ingredients. J. Food Sci. 57:19-24. doi:10.1111/j.1365-2621.1992.tb05415.x

Troutt, E. S., M. C. Hunt, D. E. Johnson, J. R. Claus, C. L. Kastner, D. H. Kropf, and S. Stroda. 1992b. Chemical, physical, and sensory characterization of ground beef containing 5 to 30 percent fat. J. Food Sci. 57:25-29. doi:10.1111/j.1365-2621.1992.tb05416.x

USDA. 2016. Retail prices for beef, pork, and poultry cuts, eggs and dairy products. USDA Economic Research Service, Washington, DC.

Wachenheim, C. J., C. Alonso, and M. Dumler. 2000. Marketing a branded fresh beef product. J. Food Prod. Mark. 6:53-79. doi:10.1300/J038v06n01_05

Wilfong, A. K., K. V. McKillip, J. M. Gonzalez, T. A. Houser, J. A. Unruh, E. A. E. Boyle, and T. G. O'Quinn. 2016. The effect of branding on consumer palatability ratings of beef strip loin steaks. J. Anim. Sci. (in press). doi:10.2527/jas.2016-0893 